\title{
Design and Implementation of University Central Kitchen Logistics Management System
}

\author{
Quanzhou Huang, ${ }^{1, *}$ \\ ${ }^{1}$ School of Computer Science, Xi'an Shiyou University, Xi'an, Shaanxi, 710065, China
}

\begin{abstract}
In order to improve the level and efficiency of university catering management, the central kitchen model is introduced into university catering logistics management, and on this basis, the logistics management information system based on central kitchen mode is proposed. This paper first analyzes the shortcomings of traditional college food management mode and introduces the concept, factors and characteristics of the central kitchen management mode. Then the requirements of the central kitchen management system are analyzed comprehensively and the requirements are modeled by UML. Combining the central kitchen management mode with information technology, the realization scheme and technical route of the system are discussed. The software structure, data model and workflow of the system are designed. Based on the above design and $\mathrm{B} / \mathrm{S}$ mode, we developed the corresponding software system. The results show that the system improves the work efficiency and reduces the cost. The university logistics management system based on central kitchen has high practical value and application prospect.
\end{abstract}

\section{Introduction}

Colleges and universities provide catering services to thousands of students and teachers every day. In the traditional management mode, there are many restaurants in a university, each of which is an independent food processing enterprise. Every restaurant is has many cooks, waiters and workers, and needs to purchase a large number of food processing equipment and environmental protection facilities. Every restaurant does the same work every day, and it leads to a large amount of waste of manpower and resources, low efficiency, and is not easy to manage [2].

In order to meet the needs of modern management, food enterprises must improve the workflow, optimize resource allocation, improve the production efficiency and reduce waste [3]. Based on this, the advanced central kitchen management mode is introduced into colleges and universities, combined with information technology, workflow technology and logistics technology to improve the management level of colleges and universities. This is a new type of enterprise management mode [4].

The central kitchen is a advanced food production base, equipped with food processing equipment and skilled technical workers. From ordering of raw materials, food production, food distribution to food sales, it may carry out unified management. The restaurants product foods no longer, but merely sell foods. The restaurant orders all foods from the central kitchen, the central kitchen products and distributes the foods $[5,6]$

There are many subsystems in the central kitchen management system. Logistics management subsystem is the most basic function. Based on information technology and workflow technology, this paper mainly researches the implementation plan of central kitchen logistics management system.

\section{Central kitchen management mode and features}

The central kitchen is also known as the food production and distribution center. The main work is to make the raw materials into semi-finished products or finished products by the user orders, and then distribute them to the restaurants [4]. The restaurants sell foods to students and staff.

In the central kitchen logistics management system, the restaurants are mainly responsible for sales. The restaurant users choose foods that are needed, and produce the food orders. The central kitchen produces finished or semi-finished products according to the orders. The logistics and distribution center send foods to the restaurants according to the orders.

The central kitchen has three advantages, including reducing production costs and ensuring food safety and easy management.

The relationship between the restaurants, consumers, central kitchen and logistics management department is shown in figure 1. 


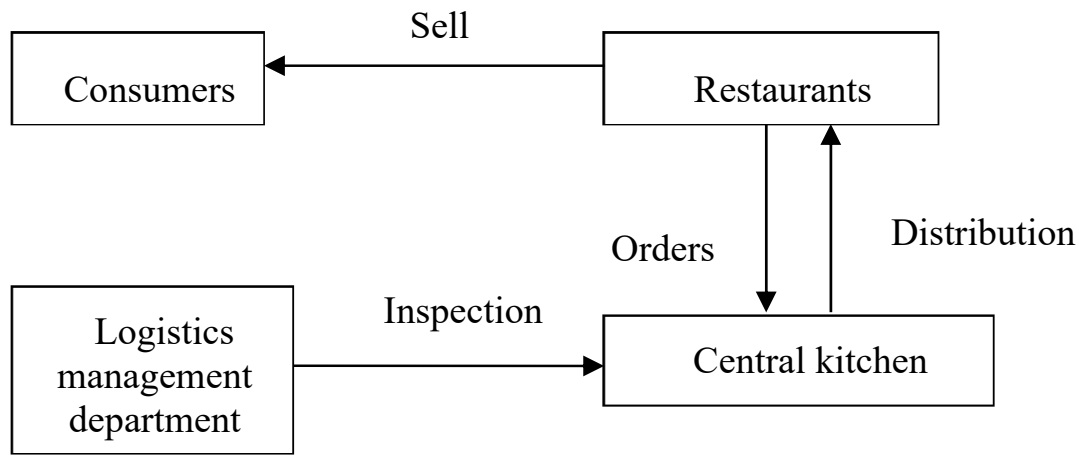

Figure1. Business relationship diagram

\section{Central kitchen management system analysis and design}

\subsection{System requirement analysis and modeling}

System users include central kitchen users (managers) and restaurant users.

Through business analysis, the main requirements of the central kitchen manager are: the user information management, foods information management, restaurants information management, orders information management, distribution information management, financial information management, information query and so on. At the end of each month, the system will automatically calculate the cost of each restaurant according to all the orders, and output various types of financial statements. The system should also provide flexible query functions for all types of users, as well as system settings, data backup and recovery functions.

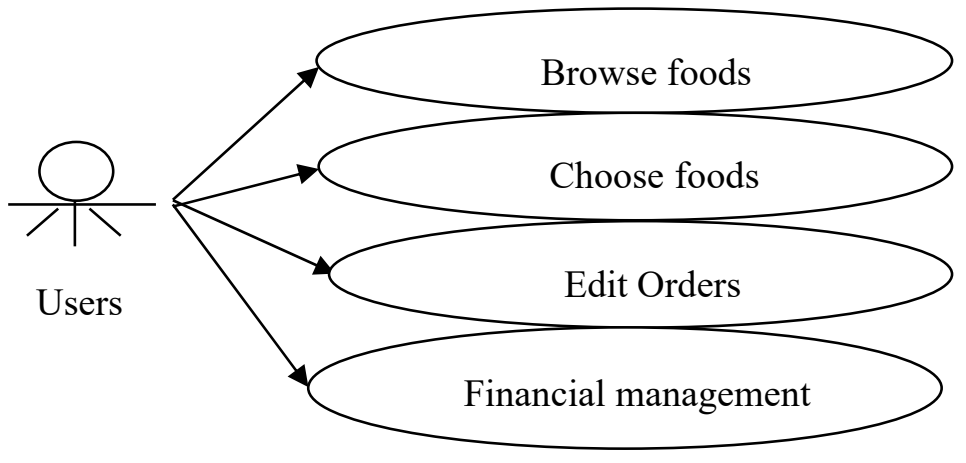

Figure2. Restaurant users use case diagram

Through restaurant business analysis, the main requirements of restaurant users are to browse foods list, select foods, produce orders, submit orders, manage financial information, and query information.

Restaurant use case diagram is shown in figure 2.

Central kitchen users use case diagram is shown in figure 3 .

\subsection{System structure design}

The university central kitchen management system is the complicated system engineering. It is composed of multiple subsystems, including order management, logistics management, warehouse management, production management, purchasing management, supply chain management, financial management, and quality control system, etc. There are complex workflows between each other. Among them, order and logistics management system is the most basic system. This paper mainly studies the order and logistics management system. 


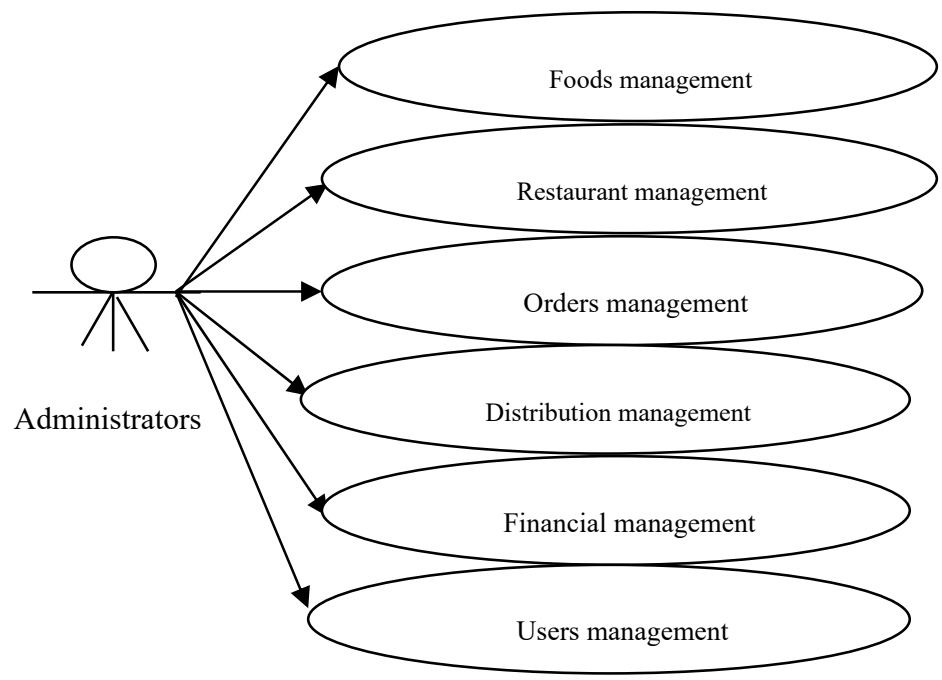

Figure3. Central kitchen users use case diagram

The system is divided into two subsystems: the restaurant subsystem as front desk and central kitchen management subsystem as background. Orders management is the key work of the system. System structure diagram is shown in figure 4.

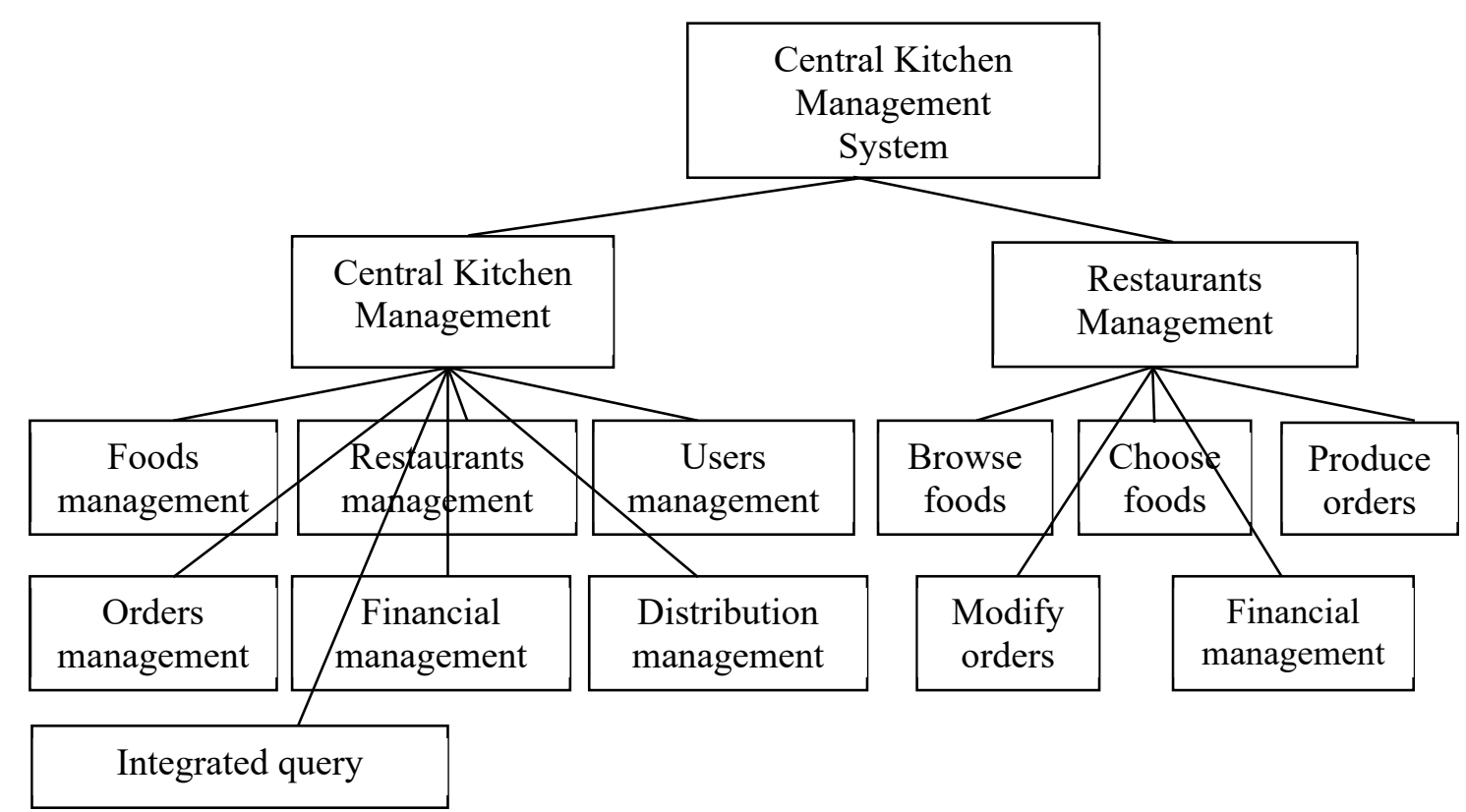

Figure4. The software structure diagram

\subsection{Order processing flow}

- First, the user login system according to user name and password.

- $\quad$ Restaurant users may view foods list, and select foods.

- $\quad$ The user fills in the orders form, including all kinds of information about the orders.

- The user may change and edit the orders before submission.

- After confirmation, the user formally submits the order.

- $\quad$ Central kitchen managers may browse the orders and send the orders to production and distribution department.
- Central kitchen managers may sum the orders according to the food types and amount every day.

- Deliverymen send the goods to the restaurants on time according to the orders.

- Deliveryman may fill in the delivery information.

- At the end of each month, the system will automatically calculate the cost of each restaurant according to all the orders.

\subsection{Database design and modeling}

Database design is an important work of system design, and it must follow the principles of database design [4]. Database design is a process to determine the database structure, database operation and data consistency constraints in the information system according to the 
business requirements, information requirements and processing requirements. The basic process of database design can be divided into four steps: conceptual design, logical design and physical design.

The task of conceptual design is to determine the conceptual structure of the database, determine the views of the data that the user sees from different angles (called the external schema), and integrate the external schema into the overall data schema of the system (called the global schema). Logical design is to transform the global schema obtained from the conceptual structure into the selected database model and optimize it. The physical design is the physical model that defines the database [6].

According to the user's business, the data analysis is carried out, and the data entities in the system and the relationship between them are determined. The database server consists of multiple data tables, and the tables are related to each other by primary and foreign keys. The designed data tables include users information table, foods information table, restaurants information table, orders and distribution information table, order details table, etc. The relationship between the tables is shown in figure 5 .

User information table is used to store users ' data, including user name, password, and other information.

Foods information table is used to store basic foods information, including food code, name, units, price, function etc.

Restaurant information table is used to store the restaurants information, mainly including restaurant code, name, address etc.

Order and distribution information table stores specific information of orders and distribution information, including order code, date, restaurant code, operator, order time, delivery time, price, total price, distribution time, deliveryman, order status etc.

Order details table stores specific information of order foods details, including order code, food code, amount, price, total price etc.

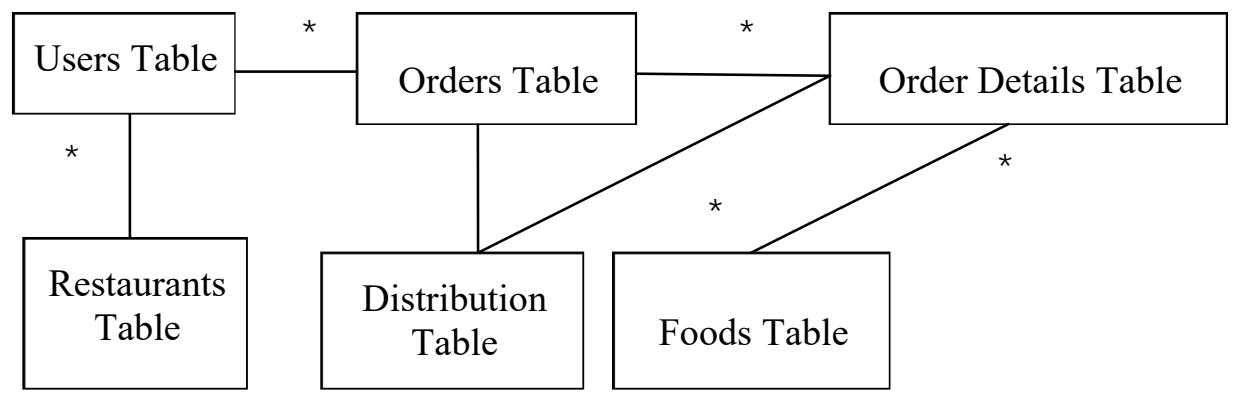

Figure5. Entity relationship diagram between tables

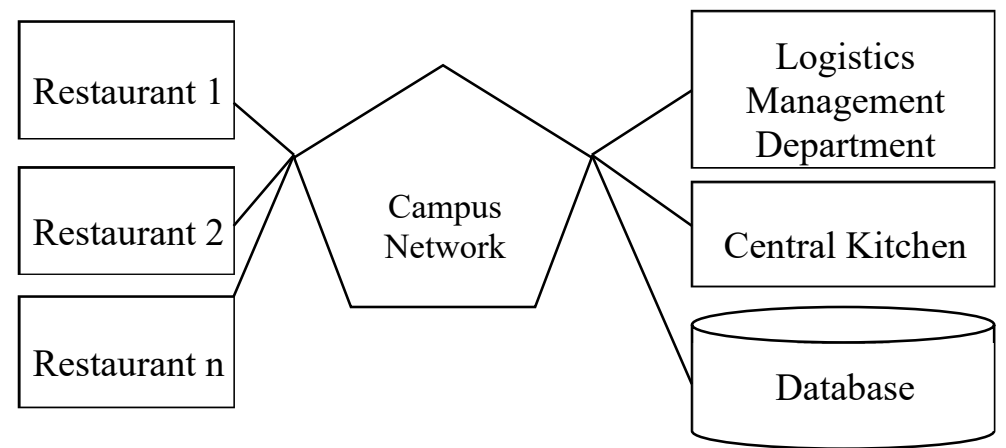

Figure6. System network structure diagram

\section{System implementation and testing}

\subsection{System development}

Figure 6 shows the software architecture of the system. The central kitchen, restaurants and data center (database server) link together by the campus network. All the data tables are stored in the data center so that the information can be shared.

The logistics management system is based on the campus network and $\mathrm{B} / \mathrm{S}$ mode, using JSP technology development, database server using Oracle. There are different permissions for different users, and the interface is friendly. The system is designed according to software engineering principles and modeled by $\operatorname{UML}[7,8]$. It has good structure, extensibility and performance.

\subsection{System testing}

Testing is the process of running software in order to find problems in the system. Information system testing includes module testing, integration testing and system testing. The methods for designing test cases are the black box method and the white box method.

The black box method mainly tests from the functional perspective to verify the correctness of the system's functions and interfaces, while the white box method mainly tests the internal paths of the program to ensure that each path and its combination can work normally.

In view of the logistics management system of the 
central kitchen in colleges and universities, the black box method is generally adopted to test, in order to find its functional errors, design loopholes and programming problems. The core sub-modules of the system, such as order management, financial management and so on, are tested in detail by using the white box method.

Through testing and integration, the identified problems were eliminated. The system has complete function, friendly interface, simple operation, safe and reliable, easy to expand, and has reached the design goal.

\section{Conclusions}

This paper analyzes the business process and characteristics of the university central kitchen logistics management, carries on the system function analysis and structural design, and realizes the corresponding software system on this basis. After running, the system has completely reached the design goal, improved the efficiency of logistics management, convenient for users to use, the technology used is completely feasible. The next step is to optimize the logistics management process and introduce the procurement management, supply chain management and warehouse management into the system. The logistics management based on central kitchen has a wide application prospect and practical value.

\section{References}

1. Li, J., Zhou, P. (2020) Design and Implementation of Logistics Enterprise Information System Based on B/S Mode. Modern Electronics Technique, 43: 90-93.

2. Ling, B. (2020) Design and Implementation of Technical Scheme on New Type "Central Kitchen" in Urban TV Station. Content Production \& Broadcasting, 47: 51-54.

3. Wang, X. (2020) Design of Warehouse Logistics Management System Based on RFID Technology from Internet of Things. Industrial Applications and Communications, 39: 155-158.

4. Huang, X. (2020) The Design of College Logistics Management System Capability Evaluation System based on Entropy Weight. International Journal of Intelligent Information and Management Science, 9: 136-141.

5. Geng, X. (2019) Logistics Management System Based on SOA Architecture. Computer Knowledge and Technology, 15: 62-64.

6. Wei, H. (2016) Information System Analysis and Design. Xidian University Press, Xian.

7. Pressman, R.S. (2012) Software Engineering: A Practitioner's Approach. China Mechanical Industry Press, Beijing.

8. Jacobson, I. (2010) The Unified Software Development Process, China Mechanical Industry Press, Beijing. 